\title{
Combined temperature-programmed reaction and in situ x-ray scattering studies of size-selected silver clusters under realistic reaction conditions in the epoxidation of propene
}

\author{
Stefan Vajda, ${ }^{1,2,3, a)}$ Sungsik Lee, ${ }^{1}$ Kristian Sell, ${ }^{4}$ Ingo Barke, ${ }^{4}$ Armin Kleibert, ${ }^{4}$ \\ Viola von Oeynhausen, ${ }^{4}$ Karl-Heinz Meiwes-Broer, ${ }^{4}$ Arantxa Fraile Rodríguez, ${ }^{5}$ \\ Jeffrey W. Elam, ${ }^{6}$ Michael M. Pellin, ${ }^{7}$ Byeongdu Lee, ${ }^{8}$ Sönke Seifert, ${ }^{8}$ and \\ Randall E. Winans ${ }^{8}$ \\ ${ }^{1}$ Chemical Sciences and Engineering Division, Argonne National Laboratory, 9700 South Cass Avenue, \\ Argonne, Illinois 60439, USA \\ ${ }^{2}$ Center for Nanoscale Materials, Argonne National Laboratory, 9700 South Cass Avenue, \\ Argonne, Illinois 60439, USA \\ ${ }^{3}$ Department of Chemical Engineering, School of Engineering and Applied Science, Yale University, \\ Hillhouse Avenue, New Haven, Connecticut 06520, USA \\ ${ }^{4}$ Institut für Physik, Universität Rostock, Universitätsplatz, 3, D-18051 Rostock, Germany \\ ${ }^{5}$ Swiss Light Source, Paul Scherrer Institut, CH-5232 Villigen PSI, Switzerland \\ ${ }^{6}$ Energy Systems Division, Argonne National Laboratory, 9700 South Cass Avenue, \\ Argonne, Illinois 60439, USA \\ ${ }^{7}$ Materials Science Division, Argonne National Laboratory, 9700 South Cass Avenue, \\ Argonne, Illinois 60439, USA \\ ${ }^{8}$ X-ray Sciences Division, Argonne National Laboratory, 9700 South Cass Avenue, \\ Argonne, Illinois 60439, USA
}

(Received 8 April 2009; accepted 4 September 2009; published online 25 September 2009)

\begin{abstract}
The catalytic activity and dynamical shape changes in size-selected nanoclusters at work are studied under realistic reaction conditions by using a combination of simultaneous temperature-programmed reaction with in situ grazing-incidence small angle x-ray scattering. This approach allows drawing a direct correlation between nanocatalyst size, composition, shape, and its function under realistic reaction conditions for the first time. The approach is illustrated in a chemical industry highly relevant selective partial oxidation of propene on a monodisperse silver nanocatalyst. The shape of the catalyst undergoes rapid change already at room temperature upon the exposure to the reactants, followed by a complex evolution of shape with increasing temperature. Acrolein formation is observed around $50{ }^{\circ} \mathrm{C}$ while the formation of the propylene oxide exhibits a sharp onset at $80{ }^{\circ} \mathrm{C}$ and is leveling off at $150{ }^{\circ} \mathrm{C}$. At lower temperatures acrolein is produced preferentially to propylene oxide; at temperatures above $100{ }^{\circ} \mathrm{C}$ propylene oxide is favored. (C) 2009 American Institute of Physics. [doi:10.1063/1.3237158]
\end{abstract}

The catalytic performance of nanometer size catalysts has been the subject of extensive theoretical and experimental studies within the catalysis and surface science communities. ${ }^{1-4}$ However, in order to elucidate the structurereactivity relationship in catalysis, well defined particles as well as the use of industrially relevant supports are required. ${ }^{5,6}$ In addition to the high-precision fabrication of the catalysts, the catalyst's activity needs to be followed under realistic reaction conditions and the evolution of catalyst's size and shape be monitored during the course of the reaction using in situ characterization tools. ${ }^{6,7}$

This communication focuses on gaining a direct correlation between nanocatalyst size and shape and its catalytic properties by combining unique methods of (1) size-selected nanocatalyst synthesis, (2) mass spectrometry, and (3) in situ imaging of size-selected nanocatalysts at work under realistic reaction conditions.

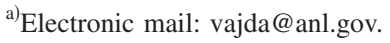

Deposition of size-preselected clusters from molecular beams is an ideal method for preparing a wide palette of nanostructures and compositions on virtually any surface, for example, highly uniform model nanocatalyst systems. ${ }^{1,2,8}$ The present monodispersed silver clusters were produced using an arc cluster ion source. ${ }^{9}$ The subsequent mass separation of the desired cluster size was achieved by an electrostatic quadrupole deflector. As support material, a $3 \mathrm{ML}$ (monolayer) thick amorphous alumina film prepared by atomic layer deposition on the top of a naturally oxidized silicon wafer was used. ${ }^{2,8,10}$ The lateral diameter and number of the supported clusters were determined by high-resolution scanning electron microscopy (SEM) on a Zeiss Field Emission SEM. Supra VP55 apparatus (Fig. 1) yielding $23.3 \mathrm{~nm}$ mean value and $1.6 \mathrm{~nm}$ width distribution at an average particle density of $1.8 \times 10^{8}$ clusters $/ \mathrm{cm}^{2}$.

Grazing incidence small angle x-ray scattering (GISAXS) was used to determine cluster size and shape during temperature-programmed reaction (TPRx). This technique has been proven to be very powerful to study particles 


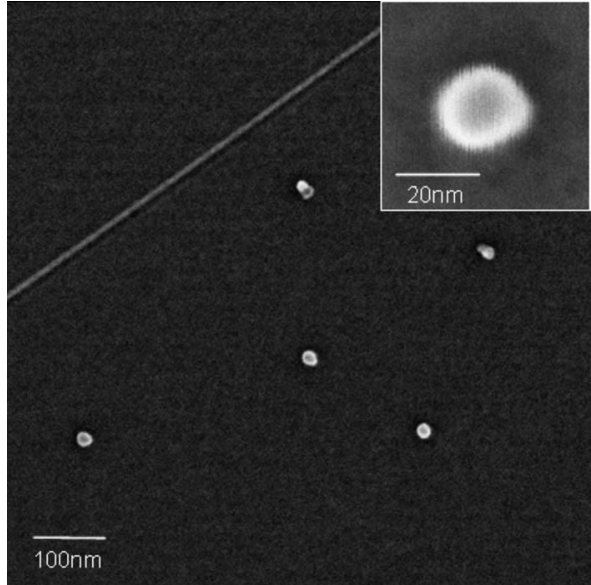

FIG. 1. SEM image of the silver nanocatalyst as deposited, with average particle size of $23.3 \mathrm{~nm}$ and width distribution of $1.6 \mathrm{~nm}$.

at surfaces and their transformations under vacuum conditions and low-pressure reactive gas environment at the nanometer ${ }^{2,11,12}$ and the subnanometer ${ }^{8}$ scales. GISAXS is sensitive to particles in the surface region and in addition to particle size, it provides particle size distribution, distance between particles and average aspect ratio of metal particles. $^{2,8,12,13}$ The GISAXS experiments were performed at the 12-ID of the Advanced Photon Source using x rays of $12.0 \mathrm{keV}$ energy in a reaction cell of our own design. The cell was sealed with mica windows and mounted on a computer controlled goniometer. As shown in Fig. 2, the x-ray beam was scattered off the surface of the sample near the critical angle $\left(\alpha_{c}=0.18\right)$ of the substrate. A 1024 $\times 1024$ pixel two-dimensional Marresearch MAR160 CCD camera was used for recording the GISAXS images from the sample. GISAXS data were collected as a function of reaction temperature and time. The two-dimensional x-ray images were analyzed by taking cuts in the $q_{y}$ direction for horizontal information and in the $q_{z}$ direction for vertical information. Scattering vectors $q$ are calculated from $(4 \pi / \lambda) \sin \theta_{f}$, where $\theta_{f}$ is the scattering half angle and $\lambda$ is the wavelength of the $\mathrm{x}$ rays. ${ }^{2,12}$ Based on the high uniformity of the silver clusters and assuming a spherical shape, the data were analyzed by the Guinier analysis, ${ }^{14}$ providing

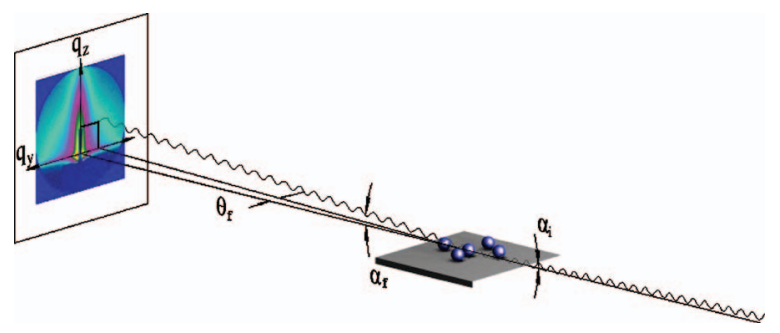

FIG. 2. Schematic of GISAXS experiment: incident angle $\alpha_{i}=0.18^{\circ}$ and scattered beam angle $\alpha_{f}$.

the horizontal and vertical particle radii of gyration $R_{g H}$ and $R_{g V}$, respectively. The diameter and height of the nanoparticles can be calculated from the radii of gyration as $2.58 R_{g H}$ and $R_{g V}$, respectively. The aspect ratio of the particles is given as $R_{g H} / R_{g V}$.

The reactants used were gases at $1 \%$ concentration in $\mathrm{He}$, the ratio for $\mathrm{C}_{3} \mathrm{H}_{6}$ and $\mathrm{O}_{2}$ was kept 2:1 by preparing the mixture in a remotely controlled gas-mixing unit consisting of calibrated mass flow controllers (Brooks model SLA5850). The reaction cell was operated in a continuous flow mode at $133 \mathrm{kPa}$ pressure and 30 SCCM (SCCM denotes cubic centimeter per minute at STP) gas flow. The products were analyzed using a differentially pumped massspectrometer (Pfeiffer Vacuum Prisma QMS 200); the reaction rates were calculated using calibrated gas mixtures and the count of deposited clusters. The temperature of the catalyst was controlled using a ceramic heater (Momentive Performance Materials Inc.) allowing heating of samples up to $600{ }^{\circ} \mathrm{C}$. The sample temperature was measured with a $K$-type thermocouple attached to the edge of the heater surface. To achieve thermal equilibrium between the heater and sample during the application of a temperature ramp, a low heating rate $\left(<1.5^{\circ} \mathrm{C} / \mathrm{min}\right)$ was used.

The evolution of the particle aspect ratio determined from GISAXS during the experiment is depicted in Fig. 3. In Fig. 3(a) the first data point (square) represents the aspect ratio of the clusters under pure helium with average diameter $(21.3 \mathrm{~nm})$ and height $(13.6 \mathrm{~nm})$ as determined by GISAXS, before introducing the reactant gas mixture. The lateral dimension of the clusters determined from GISAXS is in very good agreement with the mean cluster diameter determined
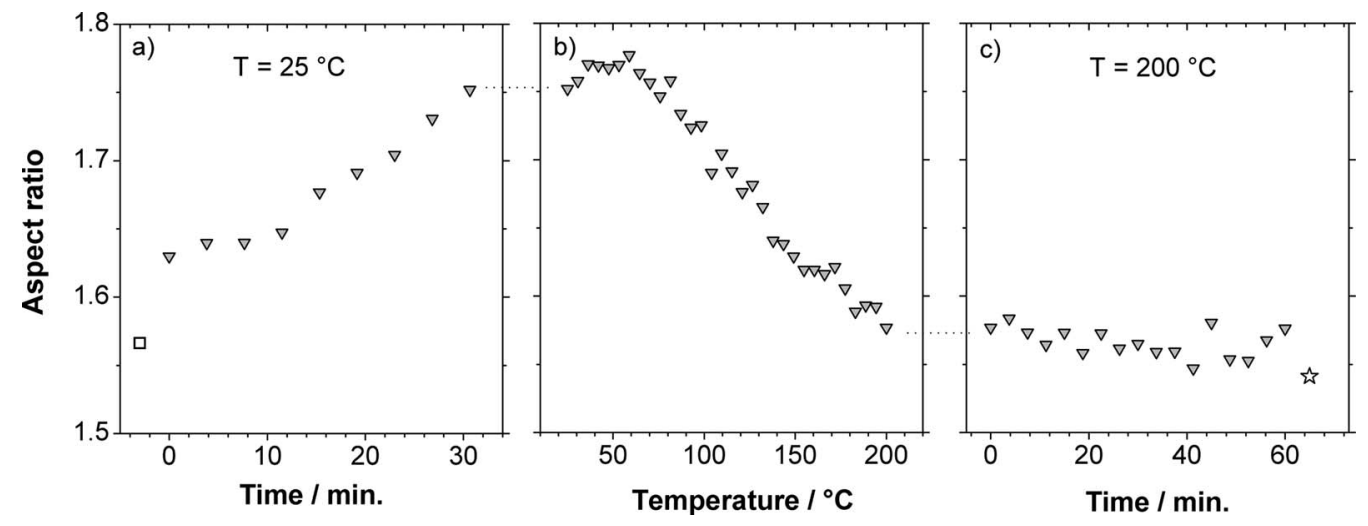

FIG. 3. (a) Square: aspect ratio of silver nanoclusters in pure helium atmosphere at room temperature. Triangles: time-dependent change in the aspect ratio after the introduction of the propene and oxygen mixture. (b) Triangles: temperature-dependent aspect ratio of the silver nanocatalyst. (c) Triangles: time-dependent aspect ratio at constant $200^{\circ} \mathrm{C}$. Star: aspect ratio after cooling back to room temperature. 
from SEM. The second data point reveals an abrupt and remarkable change at room temperature of the silver nanoparticle shape immediately after admitting propene and oxygen into the reaction cell, followed by a monotonic increase in the aspect ratio during the $30 \mathrm{~min}$ observation at room temperature. An increasing aspect ratio hints at a flattening of the silver particles, most probably driven by a significant change in the surface and interface energy, as reported by Hansen et al. ${ }^{15}$ for $\mathrm{Cu}$ nanoparticles with similar sizes. With increasing temperature, first no notable change in cluster aspect ratio is observed up to approximately $60{ }^{\circ} \mathrm{C}$, when cluster aspect ratio starts to decrease [Fig. 3(b)]. After reaching $200{ }^{\circ} \mathrm{C}$, no further change in particle aspect ratio is observed during an additional hour of the reaction at constant $200{ }^{\circ} \mathrm{C}$ [Fig. 3(c)]. The star in Fig. 3(c) represents the aspect ratio of the particles after cooling back to room temperature.

No indication of sintering was observed based on GISAXS data, which was confirmed by SEM performed after the reaction, yielding an unchanged particle size of $23.1 \pm 0.5 \mathrm{~nm}$. To identify the cause of shape change observed at room temperature, a series of experiments was performed with various gas compositions containing only oxygen, only propene, or a mixture of both reactants. Having only oxygen present in the helium carrier gas no noticeable change in cluster aspect ratio was detected. However, a mixture of propene with oxygen in helium or propene alone induced the same changes in cluster shape, which indicates that propene induces changes in the cluster shape at room temperature. This is supported by an earlier study of Argo et al., ${ }^{3}$ revealing that propene ligands cause changes in interatomic distances in clusters and affect cluster/support interaction in $\mathrm{Ir} / \mathrm{Al}_{2} \mathrm{O}_{3}$ and $\mathrm{Ir} / \mathrm{MgO}$ catalysts. Moreover, Nijhuis et $a l .{ }^{16}$ found significant adsorption of propene to titaniasupported gold nanoparticles and the formation of bidentate propoxy species being a critical step in the epoxidation of propene on $\mathrm{Au} / \mathrm{TiO}_{2}$. The binding of ligands may alter the surface energy of the nanoparticle and the strengths of the interaction at the nanoparticle-support interface inducing dramatic shape changes similar to the observations by Hansen et al. ${ }^{15}$

As far as the temperature-dependent shape change above $60{ }^{\circ} \mathrm{C}$ is concerned, in addition to the interaction of the reactants with the clusters several other factors can be considered, such as the change in the chemistry of the support and surface oxide formation on the silver clusters. The alumina surface is $\mathrm{OH}$ terminated ${ }^{17}$ with water adsorbed on it. As reported, water starts to desorb from a hydroxylated $\alpha$-alumina surface at $47^{\circ} \mathrm{C}$, reaching maximum desorption rates at $102{ }^{\circ} \mathrm{C}^{18}$ In a control experiment, desorption of water from our support was observed as well, which may also cause morphology changes in nanoparticle morphology. Moreover, partial dehydroxylation of the support during the reaction can affect support-metal particle interactions which may lead to changes in particle morphology as well. ${ }^{19}$ Another possible factor leading to morphology changes is the reduction and reoxidation of the surface of the metal clusters during the reaction. ${ }^{20-23}$

To study the catalytic activity, we measured the production of propylene oxide as a function of temperature. Figure
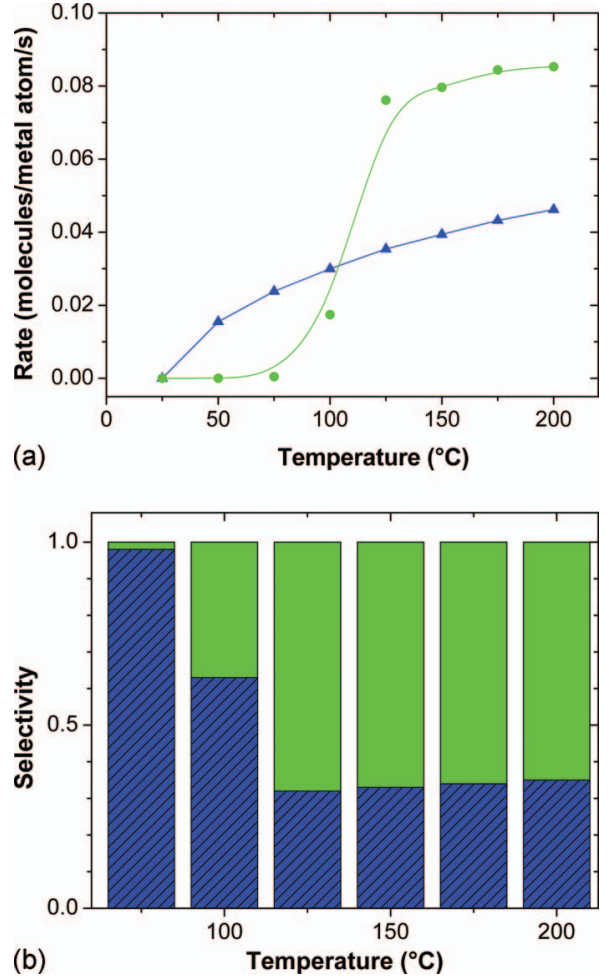

FIG. 4. Top: rate of propylene oxide (circles) and acrolein (triangles) formed per surface silver site as a function of temperature. Bottom: temperature-dependent selectivity toward propylene oxide (solid) and acrolein (stripes).

4 shows the rate of propylene oxide and acrolein formation per surface silver atom after correction to background signal levels. The background ion signal intensities for propylene oxide and acrolein measured on a blank alumina support were below $4 \%$ and $15 \%$ of the corresponding ion signals in the presence of the silver nanocatalyst, respectively. The intensity of the ion signal of $\mathrm{CO}_{2}$ was flat over the entire temperature range.

The catalyst exhibits a sharp onset of activity at around 50 and $80{ }^{\circ} \mathrm{C}$ for acrolein and propylene oxide, respectively, with the propylene oxide formation leveling off at $150{ }^{\circ} \mathrm{C}$. No further change in activity was observed during an additional hour of reaction at constant $200{ }^{\circ} \mathrm{C}$. Acrolein formation is preferred to propylene oxide formation at temperatures up to $100{ }^{\circ} \mathrm{C}$; at higher temperatures propylene oxide production prevails. It is noteworthy that the onset of catalytic activity takes place in the identical temperature range as the change in cluster shape (cf. Fig. 3). Moreover, $150{ }^{\circ} \mathrm{C}$ is the temperature at which a formation of subsurface oxygen in silver with molecular oxygen was reported on silver catalysts. ${ }^{21,24}$ The role of oxygen on silver particles in oxidation reactions was described in several papers, ${ }^{21,22,24,25}$ including oxide formation ${ }^{26}$ (see above).

The epoxidation of propene on silver catalysts with molecular oxygen has been a topic of a large number of papers, including the role of promoters. These catalysts posses low conversion and poor selectivity toward propylene oxide. ${ }^{23,27,28}$ However, it is not clear whether the intrinsic properties of the silver nanoparticles or wide distribution of silver particle sizes are the main cause of the poor selectivity 
reported by Zemichael et $a l^{23}$ for unpromoted and $K$-promoted silver catalysts. Moreover, the used $K$ promoter also affected the size of silver particles formed, producing $20-40 \mathrm{~nm}$ or $4-70 \mathrm{~nm}$ size distributions with and without the promoter, respectively. Similar effect of promoter on the particle size was also reported by Yao et $a l^{28}$ A very elegant illustration of the size effect and possible reaction channels in silver-mediated propene oxidation was reported by Roithova and Schroder ${ }^{29}$ on gas-phase $\mathrm{Ag}_{2} \mathrm{O}^{+}$clusters- the smallest model of silver epoxidation catalysts - revealing a competing $\mathrm{C}-\mathrm{H}$ bond activation channel resulting in poorer selectivity toward epoxide formation.

In conclusion, we have shown that the combination of size-selected cluster deposition, TPRx and in situ x-ray scattering techniques, allows the catalytic properties of sizepreselected catalyst to be studied while simultaneously monitoring the evolution of particle shape under realistic reaction conditions. As an example we have investigated the reactivity of $23 \mathrm{~nm}$ sized silver clusters in the epoxidation of propene. Our approach revealed that the silver clusters are highly fluxional, reversibly changing their shape depending on the environment even at room temperature. The shape changes were accompanied by distinct changes in the acrolein and propylene oxide formation during the reaction. This demonstrates the promising potential of this new approach, where the catalytic activity of nanocatalysts is accompanied by dramatic changes in their shape and thus, opens new ways to elucidate the correlation between catalyst function and catalyst size, composition, and shape.

The work at Argonne National Laboratory was supported by the U.S. Department of Energy, BES-Chemical Sciences, Materials Sciences and BES-Scientific User Facilities under Contract No. DE-AC-02-06CH11357 with UChicago Argonne, LLC, Operator of Argonne National Laboratory. S.V. gratefully acknowledges the support by the (U.S.) Air Force Office of Scientific Research. The work at the Universität Rostock was supported by the Deutsche Forschungsgemeinschaft, Schwerpunktprogramm 1153 "Cluster in Kontakt mit Oberflächen" (German Science Foundation, Priority Program "Clusters at Surfaces").

${ }^{1}$ B. Yoon, H. Häkkinen, U. Landman, A. S. Wörz, J.-M. Antonietti, S. Abbet, K. Judai, and U. Heiz, Science 307, 403 (2005); K. Judai, A. S. Wörz, S. Abbet, and U. Heiz, J. Am. Chem. Soc. 126, 2732 (2004).

${ }^{2}$ B. Lee, S. Seifert, S. J. Riley, G. Tikhonov, N. A. Tomczyk, S. Vajda, and R. E. Winans, J. Chem. Phys. 123, 074701 (2005); S. Lee, C. Fan, T. Wu, and S. L. Anderson, ibid. 123, 124710 (2005); S. Vajda, R. E. Winans, J. W. Elam, B. Lee, M. J. Pellin, S. J. Riley, S. Seifert, G. Y. Tikhonov, and N. A. Tomczyk, "In situ GISAXS studies of the thermal stability and temperature induced growth of supported cluster-based platinum and gold nanoparticles," Preprints of Symposia (American Chemical Society, Washington, DC, 2005), Vol. 50, pp. 190-191.

${ }^{3}$ A. M. Argo, J. F. Odzak, F. S. Lai, and B. C. Gates, Nature (London) 415, 623 (2002).

${ }^{4}$ M. Haruta, Catal. Today 36, 153 (1997); M. Valden, X. Lai, and D. W. Goodman, Science 281, 1647 (1998); C. R. Henry, Surf. Sci. Rep. 31, 231 (1998); H.-J. Freund, Surf. Sci. 500, 271 (2002).

${ }^{5}$ A. T. Bell, Science 299, 1688 (2003).

${ }^{6}$ K. Arve, K. Svennerberg, F. Klingstedt, K. Eranen, L. R. Wallenberg,
J.-O. Bovin, L. Capek, and D. Y. Murzin, J. Phys. Chem. B 110, 420 (2006).

${ }^{7}$ E. Ruckenstein and S. H. Lee, J. Catal. 109, 100 (1988).

${ }^{8}$ S. Vajda, R. E. Winans, J. W. Elam, B. Lee, M. J. Pellin, S. Seifert, G. Y. Tikhonov, and N. A. Tomczyk, Top. Catal. 39, 161 (2006); R. E. Winans, S. Vajda, G. E. Ballentine, J. W. Elam, B. Lee, M. J. Pellin, S. Seifert, G. Y. Tikhonov, and N. A. Tomczyk, ibid. 39, 145 (2006).

${ }^{9}$ A. Kleibert, J. Passig, K. H. Meiwes-Broer, M. Getzlaff, and J. Bansmann, J. Appl. Phys. 101, 114318 (2007).

${ }^{10}$ J. W. Elam and S. M. George, Chem. Mater. 15, 1020 (2003).

${ }^{11}$ G. Renaud, R. Lazzari, C. Revenant, A. Barbier, M. Noblet, O. Ulrich, F. Leroy, J. Jupille, Y. Borensztein, C. R. Henry, J.-P. Deville, F. Scheurer, J. Mane-Mane, and O. Fruchart, Science 300, 1416 (2003).

${ }^{12}$ R. E. Winans, S. Vajda, B. Lee, S. J. Riley, S. Seifert, G. Y. Tikhonov, and N. A. Tomczyk, J. Phys. Chem. B 108, 18105 (2004).

${ }^{13}$ A. Barbier, G. Renaud, and J. Jupille, Surf. Sci. 454-456, 979 (2000).

${ }^{14}$ A. Guinier, G. Fournet, C. B. Walker, and K. L. Yudowitch, Small Angle Scattering of X-Rays (Wiley, New York, 1955).

${ }^{15}$ P. L. Hansen, J. B. Wagner, S. Helveg, J. R. Rostrup-Nielsen, B. S. Clausen, and H. Topsoe, Science 295, 2053 (2002).

${ }^{16}$ T. A. Nijhuis, T. Visser, and B. M. Weckhuysen, Angew. Chem., Int. Ed. 44, 1115 (2005); T. A. Nijhuis, E. Sacaliuc, A. M. Beale, A. M. J. van der Eerden, J. C. Schouten, and B. M. Weckhuysen, J. Catal. 258, 256 (2008); T. A. Nijhuis, E. Sacaliuc-Parvulescu, N. S. Govender, J. C. Schouten, and B. M. Weckhuysen, ibid. 265, 161 (2009).

${ }^{17}$ G. Xiong, J. W. Elam, H. Feng, C. Y. Han, H.-H. Wang, L. E. Iton, L. A. Curtiss, M. J. Pellin, M. Kung, H. Kung, and P. C. Stair, J. Phys. Chem. B 109, 14059 (2005).

${ }^{18}$ J. W. Elam, C. E. Nelson, M. A. Cameron, M. A. Tolbert, and S. M. George, J. Phys. Chem. B 102, 7008 (1998).

${ }^{19}$ P. J. Eng, T. P. Trainor, G. E. Brown, Jr., G. A. Waychunas, M. Newville, S. R. Sutton, and M. L. Rivers, Science 288, 1029 (2000); J. A. Kelber, C. Niu, K. Shepherd, D. R. Jennison, and A. Bogicevic, Surf. Sci. 446, 76 (2000); Z. Lodziana and J. K. Norskov, J. Chem. Phys. 115, 11261 (2001); Z. Lodziana, J. K. Norskov, and P. Stoltze, ibid. 118, 11179 (2003).

${ }^{20}$ R. Serna, D. Babonneau, A. Suárez-García, C. N. Afonso, E. Fonda, A. Traverse, A. Naudon, and D. E. Hole, Phys. Rev. B 66, 205402 (2002); M. A. Barteau and R. J. Madix, J. Am. Chem. Soc. 105, 344 (1983); J. T. Ranney and S. R. Bare, Surf. Sci. 382, 266 (1997); T. A. Nijhuis, M. Makkee, J. A. Moulijn, and B. M. Weckhuysen, Ind. Eng. Chem. Res. 45, 3447 (2006).

${ }^{21}$ M. Rocca, L. Vattuone, L. Savio, F. B. d. Mongeot, U. Valbusa, G. Comelli, S. Lizzit, A. Baraldi, G. Paolucci, J. A. Groeneveld, and E. J. Baerends, Phys. Rev. B 63, 081404 (2001).

${ }^{22}$ V. I. Bukhtiyarov and V. V. Kaichev, J. Mol. Catal. A: Chem. 158, 167 (2000).

${ }^{23}$ F. W. Zemichael, A. Palermo, M. S. Tikhov, and R. M. Lambert, Catal. Lett. 80, 93 (2002).

${ }^{24}$ V. I. Bukhtiyarov, V. V. Kaichev, and I. P. Prosvirin, J. Chem. Phys. 111, 2169 (1999).

${ }^{25}$ A. Kokalj, A. D. Corso, S. d. Gironcoli, and S. Baroni, Surf. Sci. 532535, 191 (2003); M. Atkins, J. Couves, M. Hague, B. H. Sakakini, and K. C. Waugh, J. Catal. 235, 103 (2005); C. Stegelmann and P. Stoltze, ibid. 226, 129 (2004); C. J. Bertole and C. A. Mims, ibid. 184, 224 (1999); C. T. Campbell, Surf. Sci. 157, 43 (1985).

${ }^{26}$ A. Klust and R. J. Madix, Surf. Sci. 600, 5025 (2006); J. Schnadt, A. Michaelides, J. Knudsen, R. T. Vang, K. Reuter, E. Lægsgaard, M. Scheffler, and F. Besenbacher, Phys. Rev. Lett. 96, 146101 (2006); M. Schmid, A. Reicho, A. Stierle, I. Costina, J. Klikovits, P. Kostelnik, O. Dubay, G. Kresse, J. Gustafson, E. Lundgren, J. N. Andersen, H. Dosch, and P. Varga, ibid. 96, 146102 (2006); A. Reicho, A. Stierle, I. Costina, and H. Dosch, Surf. Sci. 601, L19 (2007); X. Bao, M. Muhler, R. Schlögl, and G. Ertl, Catal. Lett. 32, 185 (1995); D. S. Su, T. Jacob, T. W. Hansen, D. Wang, R. Schlögl, B. Freitag, and S. Kujawa, Angew. Chem., Int. Ed. 47, 5005 (2008).

${ }^{27}$ M. Luo, J. Lu, and C. Li, Catal. Lett. 86, 43 (2003).

${ }^{28}$ W. Yao, G. Z. Lu, Y. L. Guo, Y. Guo, Y. Q. Wang, and Z. G. Zhang, J. Mol. Catal. A: Chem. 276, 162 (2007).

${ }^{29}$ J. Roithova and D. Schroder, J. Am. Chem. Soc. 129, 15311 (2007). 